\title{
BEACH CHANGES CAUSED BY EXTENSION OF OFFSHORE BREAKWATER AND LIMITATIONS OF ARTIFICIAL REEFS CONSTRUCTED AS A MEASURE AGAINST BEACH EROSION
}

\author{
Yasuhito Noshi ${ }^{1}$, Takaaki Uda ${ }^{2}$ and Yukiyoshi Hoshigami ${ }^{3}$
}

\begin{abstract}
Beach changes on a pocket beach of $6.5 \mathrm{~km}$ length bounded by Ryugu and Unoko Points facing the Pacific Ocean in Fukushima Prefecture were investigated using the contour-line-change model. The shoreline recession and excess deposition of sand in the central and southern parts of the study area, respectively, between 1980 and the 1990s were triggered by the wave-sheltering effect due to the extension of the offshore breakwater of Hirakata fishing port south of the study area. Although artificial reefs were constructed in the eroded area of the study area as a measure against beach erosion, their protective effect was limited because the wave-sheltering effect of the offshore breakwater of the fishing port is much larger than that of the artificial reefs.
\end{abstract}

Keywords: wave-sheltering effect; beach erosion; anthropogenic factors; artificial reef; sector-by-sector system

\section{INTRODUCTION}

When an offshore breakwater is constructed near the end of a pocket beach, sand is deposited in the wave-shelter zone of the offshore breakwater, and beach erosion occurs on the nearby coast. A typical example can be found in the vicinity of Oharai Port facing the Pacific Ocean (Matsu-ura et al., 2010), where a wave-shelter zone was formed following the construction of an offshore breakwater, resulting in the deposition of fine sand in the wave-shelter zone and beach erosion on the nearby coast. In this case, both the port authority responsible for port construction and the organization in charge of shore protection works were part of the Ibaraki Prefectural Government, and therefore, various adjustments were possible. Similar beach erosion has occurred on a pocket beach bounded by Ryugu and Unoko Points in Fukushima Prefecture. However, in this case, the offshore breakwater was constructed south of Fukushima Prefecture by a different organization, that is, the Ibaraki Prefectural Government, without any detailed planning, and the measures against beach erosion were independently carried out without considering the construction of the fishing port. Thus, various measures, including the construction of artificial reefs, became incoherent and ineffective. In this study, we analyze this situation and propose the necessity of comprehensive measures over an extensive area exceeding the jurisdiction of individual authorities separated by a sector-by-sector system to prevent beach erosion. For this purpose, we first analyzed aerial photographs obtained between 1975 and 2006, and also sampled beach materials on December 25, 2009. Then, we reproduced beach changes using the contour-line-change model developed by Serizawa et al. (2003) and discuss the structural system that will help prevent beach deterioration.

\section{AERIAL PHOTOGRAPHS OF STUDY AREA}

The study area is a pocket beach of $6.5 \mathrm{~km}$ length bounded by Ryugu and Unoko Points at the north and south ends, respectively, in Fukushima Prefecture, as shown in Fig. 1. In the northern part of the study area, the Same River with a catchment area of $600 \mathrm{~km}^{2}$ flows into the Pacific Ocean. The location of local coasts, such as the Ueda-Iwama, Ueda-Sanuka, Suga, Sekita and Kokozura coasts, is shown in Fig. 1, where the names of the coasts are abbreviated by "Iwama" and "Sanuka" for "UedaIwama" and "Ueda-Sanuka", respectively.

The beach changes observed in the study area were investigated using aerial photographs obtained between 1975 and 2006. Of the five aerial photographs obtained, the three photographs obtained in 1975, 1986 and 2006 were selected (Fig. 2). The Same River markedly meandered over $1.5 \mathrm{~km}$ northward near the river mouth and flowed into the sea along Ryugu Point at the north end of the study area in 1975, as shown in Fig. 2(a). The beach width was as large as $100 \mathrm{~m}$ in the northern part and 60 $\mathrm{m}$ on the Sekita coast located in the southern part of the study area. In contrast, there was no sandy beach near Nakoso fishing port at the south end of the study area.

\footnotetext{
${ }_{1}^{1}$ ICOMNET, Ltd., Elevage Kanda-Nishikicho Bldg., 3-16-11, Kanda-Nishikicho, Chiyoda, Tokyo 101-0054 Japan

${ }^{2}$ Public Works Research Center, 1-6-4 Taito, Taito, Tokyo 110-0016, Japan

${ }^{3}$ Kokusai Kogyo Co., Ltd., 3-6-1 Asahigaoka, Hino, Tokyo 191-0065, Japan
} 


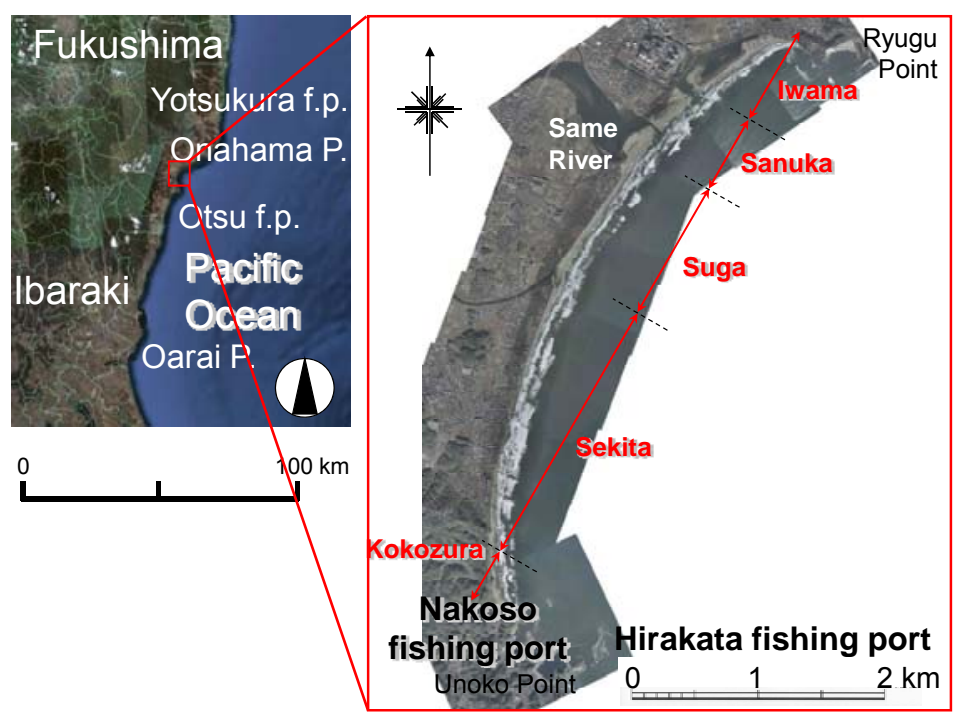

Figure 1. Location of study area in Fukushima Prefecture, Japan.

In 1986, a training jetty of the Same River was extended on the left bank, and the river, which markedly meandered northward, was forced to flow out along this training jetty in the central part of the coast, as shown in Fig. 2(b). Simultaneously, the river mouth located at the north end of the study area was fully enclosed because of the disappearance of river currents, and sand was transported inside the river as a result of the opening of the river mouth bar. In addition, sand was transported landward by wave overtopping in the previous river mouth, resulting in the narrowness of the previous river. Near the south end of the coast, six detached breakwaters were constructed and tombolos were formed behind the detached breakwaters. Also, artificial reefs were constructed up to October 2006 on the Sekita coast in the central part of the study area as a measure against beach erosion that had been occurring.

Figure 2(c) shows the aerial photograph obtained in December 2006 after the construction of the artificial reefs. The breaker zone (white zone in the photograph) along the shoreline was formed by wave breaking on the artificial reefs. By comparing Figs. 2(a) and 2(c), it is seen that the width of the sand bar significantly increased at the previous mouth of the Same River. Furthermore, near Nakoso fishing port located at the south end of the study area, the shoreline seemed to have significantly advanced owing to the construction of six detached breakwaters. In the south end of the area, a wide beach was formed around the detached breakwaters, and the excess deposition of sand around the detached breakwaters caused the disappearance of the seaweed floor of the natural reef.

Although the aerial photographs shown in Fig. 2 suggest that the deposition of sand near the south end is owing to the construction of the detached breakwaters, it is closely related to the extension of the port breakwaters in an extensive area including the coasts surrounding the study area.

Regarding the construction of the facilities related to the beach changes in the study area, the offshore breakwater of Hirakata fishing port in Ibaraki Prefecture, located south of Nakoso fishing port, was being constructed until 1995 along with the construction of the offshore breakwater of Nakoso fishing port until 1999. Furthermore, the offshore breakwater of Onahama Port, located north of the study area, was also extended up to 1976 (the offshore part: up to 1991). After the construction of these offshore breakwaters, the shoreline advanced behind the wave-shelter zones, whereas outside the wave-shelter zones sand was transported away by longshore sand transport toward the wave-shelter zones, resulting in shoreline recession.

It was assumed that the deposition of sand near the south end of the pocket beach was due to the effect of the detached breakwaters, and the demolition of these detached breakwaters was effective to recover the original coastal environment. However, the exact causes of the deposition of sand near the south end have not yet been identified. 
(a) 1975

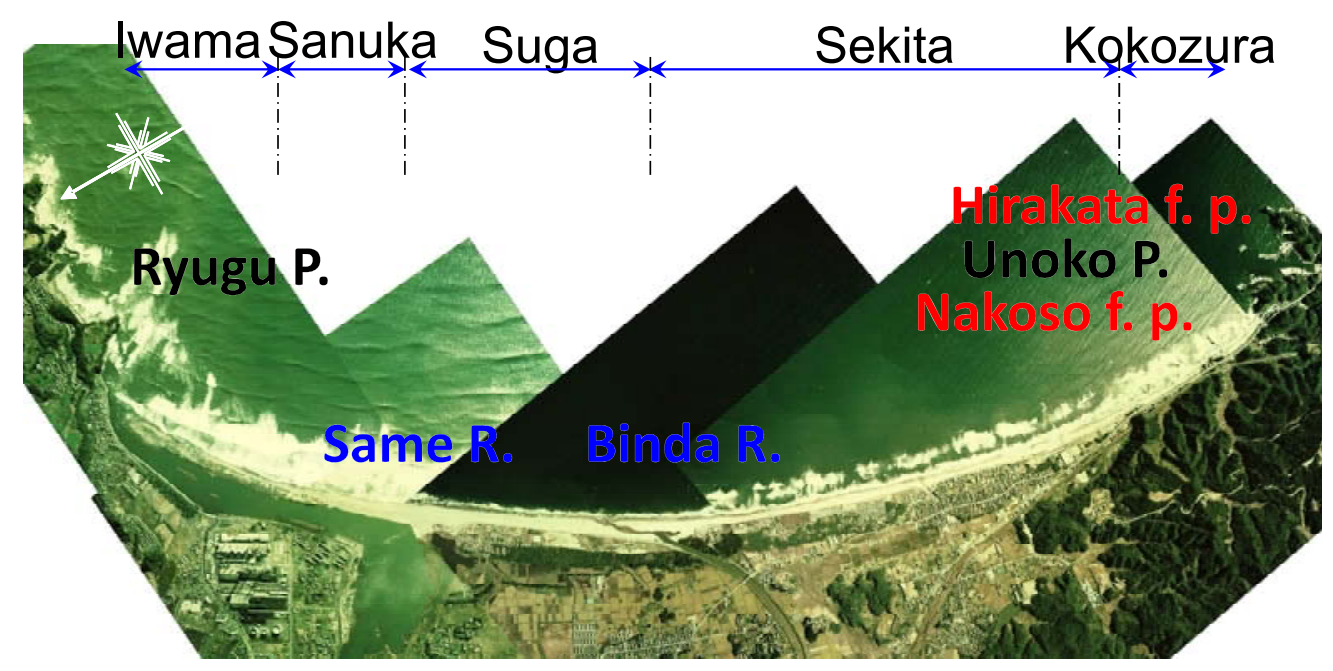

(b) 1986

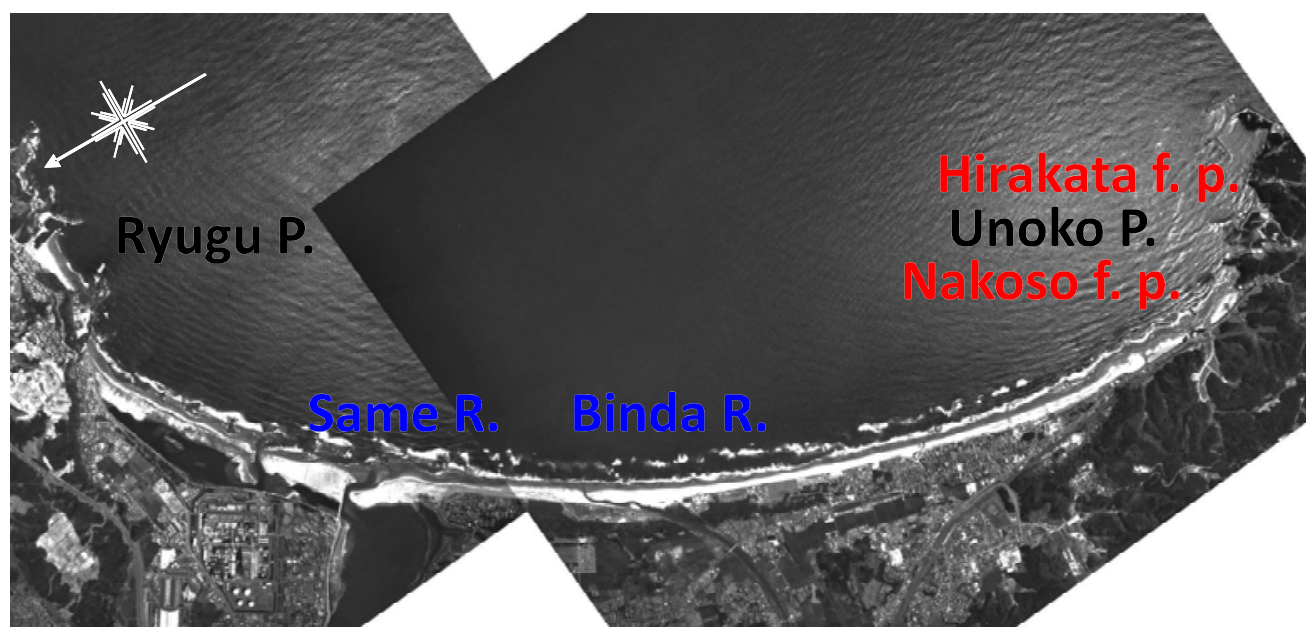

(c) 2006

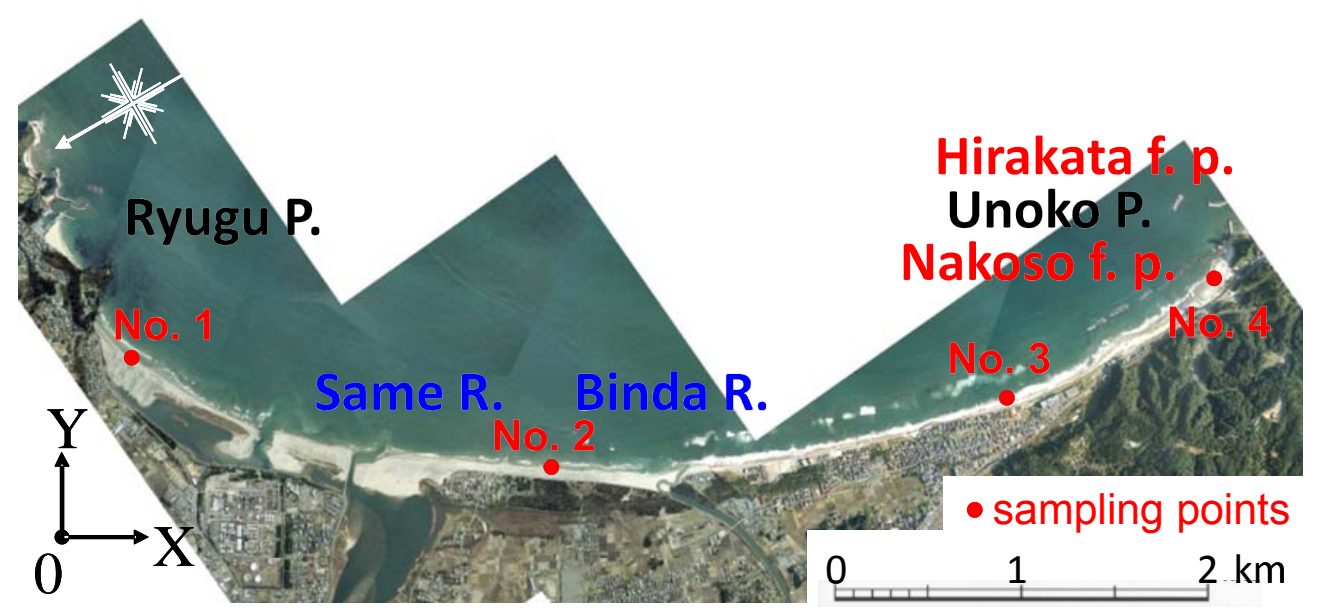

Figure 2. Aerial photographs of study area in 1975, 1986 and 2006. 


\section{SHORELINE CHANGES}

Figure 3 shows the shoreline configurations measured in 1975 and 2006 together with the locations of the six detached breakwaters constructed near the south end of the study area and artificial reefs with a crown height of $1.65 \mathrm{~m}$ below mean sea level and a width of $10 \mathrm{~m}$. Artificial reefs were constructed with lengths of $750 \mathrm{~m}$ and $2300 \mathrm{~m}$ on the Suga and Sekita coasts, respectively, up to 2006, as shown in Fig. 3.

Figure 4 shows the shoreline changes in the study area between 1975 and 2006. The shoreline advanced near the previous river mouth of the Same River located at the north end of the beach. This shoreline advance is assumed to be due to the disappearance of the river discharge, because a training jetty was extended at $X=1.6 \mathrm{~km}$, and the river directly flowed into the sea. The shoreline receded by 20-30 m behind the artificial reef between $X=2$ and $3 \mathrm{~km}$ on the Suga coast, whereas the shoreline recession increased to as large as $40 \mathrm{~m}$ on average on the Sekita coast located between $X=3.5$ and 5.5 $\mathrm{km}$, and gradually increased southward from the location of $X=4 \mathrm{~km}$ with a maximum value of $50 \mathrm{~m}$ immediately north of the detached breakwaters. In contrast, sand was markedly deposited near the south end of the pocket beach with a shoreline advance of $163 \mathrm{~m}$ until 2006 at the south end.

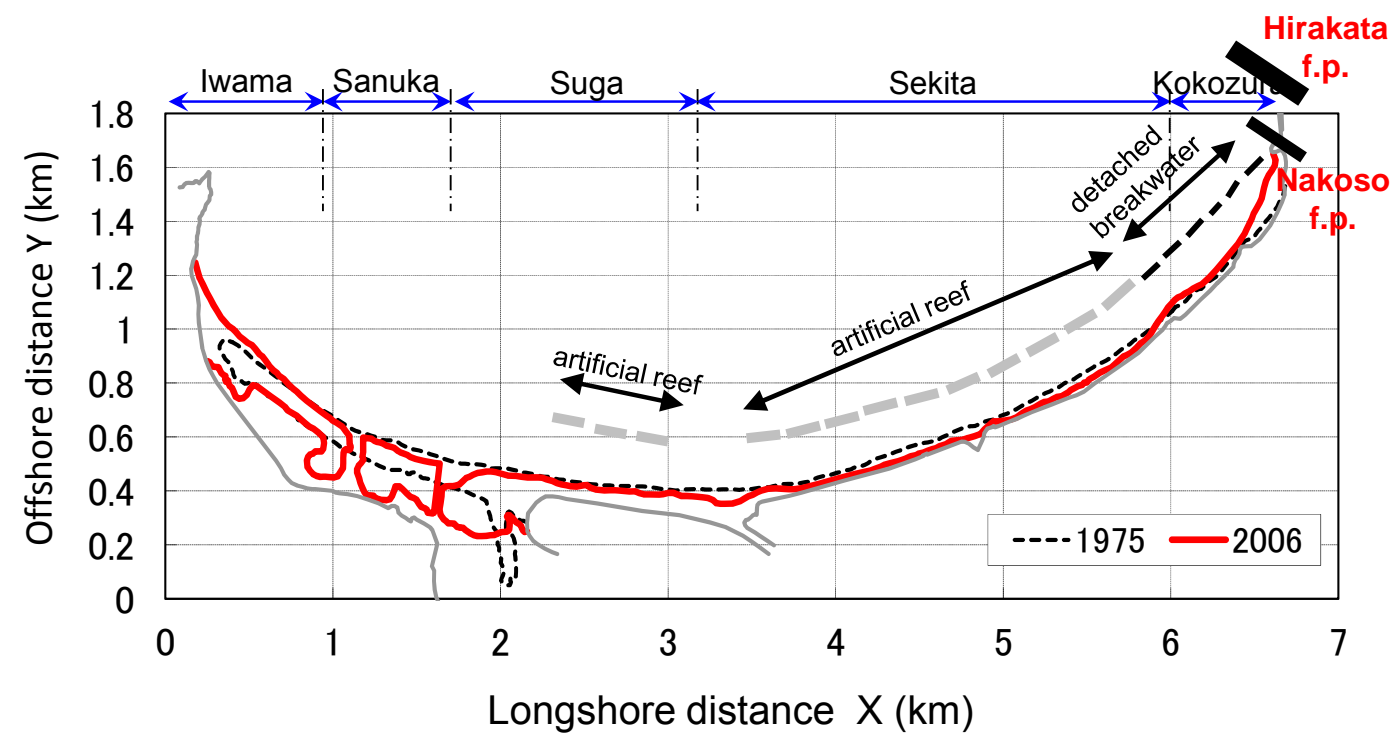

Figure 3. Shoreline configurations in 1975 and 2006.

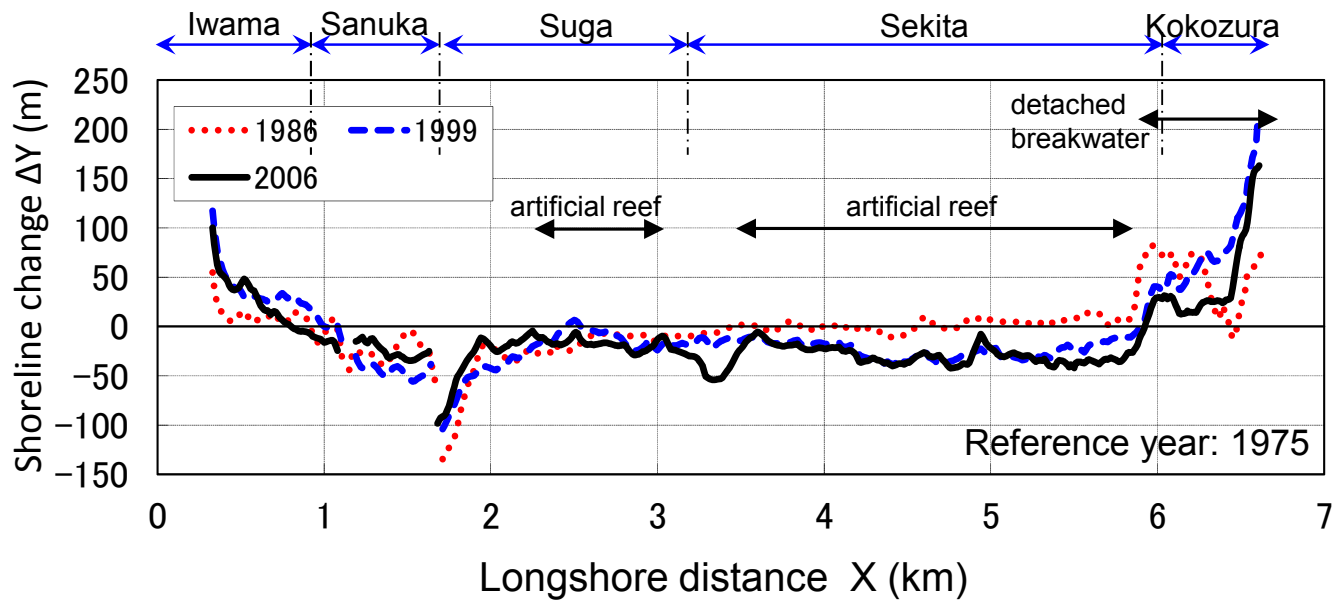

Figure 4. Shoreline changes with reference to that in 1975. 
Although the shoreline advanced until 1986, forming cuspate forelands behind the three detached breakwaters located on the north side, after that the shoreline tended to advance in the vicinity of the south end of the beach until 2006, and the cuspate forelands behind the detached breakwaters did not increase in size. These findings imply that beach erosion on the Sekita coast and the deposition of sand near the south end of the pocket beach are due not only to the wave-sheltering effect of the detached breakwaters but also to the construction of the offshore breakwater of Hirakata fishing port beyond the south point. Furthermore, although artificial reefs have been constructed as a measure against beach changes in an extensive area since 2004, their effect on recovering the beach on the Sekita coast has been limited.

The coast under study is a pocket beach bounded by headlands at both ends, and therefore the cause of severe beach changes is considered to be the imbalance of the deposition of sand triggered by anthropogenic factors. Because the sand supplied from the Same River contributes to the overall volume of sand deposited on the coast, the decrease in the volume of sand supplied from this river is assumed not to be related to erosion.

\section{GRAIN SIZE COMPOSITION OF FORESHORE MATERIALS}

On December 25, 2009, foreshore materials were sampled at four locations, as shown in Fig. 2(c), and sieve analysis was carried out to obtain the grain size composition of the foreshore materials. The sampling points numbered 1, 2, 3 and 4 were located near the previous mouth of the Same River at the north end, on the Suga and Sekita coasts and behind Nakoso fishing port, respectively. Figure 5 shows the grain size composition. At site No. 1, where sand has been deposited and the shoreline has advanced in recent years, fine and medium-size sand contents were found to be $37.2 \%$ and $62.8 \%$, respectively, and the primary part was composed of medium-size sand. At site Nos. 2 and 3, in the central part of the beach where beach erosion occurred with shoreline recession, the beach materials were mostly composed of medium-size sand, the contents of which were as high as $87.1 \%$ and $78.1 \%$, respectively. In contrast, at site No. 4, located at the south end where sand was deposited, the fine and medium-size sand contents were $59.9 \%$ and $40.0 \%$, respectively, and the fine sand content was markedly higher than elsewhere.

These grain size composition distributions mean that sand was deposited on the study coast owing to the formation of the wave-shelter zone on the south side associated with the extension of the offshore breakwater of Hirakata fishing port in Ibaraki Prefecture and that fine sand was selectively deposited in this wave-shelter zone. Furthermore, the fact that the fine sand content on the Kokozura coast is higher than those on the Sekita and Suga coasts, where the medium-size sand content is high, suggests that fine sand was selectively transported south from the Sekita and Suga coasts and deposited on the Kokozura coast. Simultaneously, coarser sand was left on the Sekita and Suga coasts outside the wave-shelter zone of the offshore breakwater as in the case of Oharai Port (Matsu-ura et al., 2010).

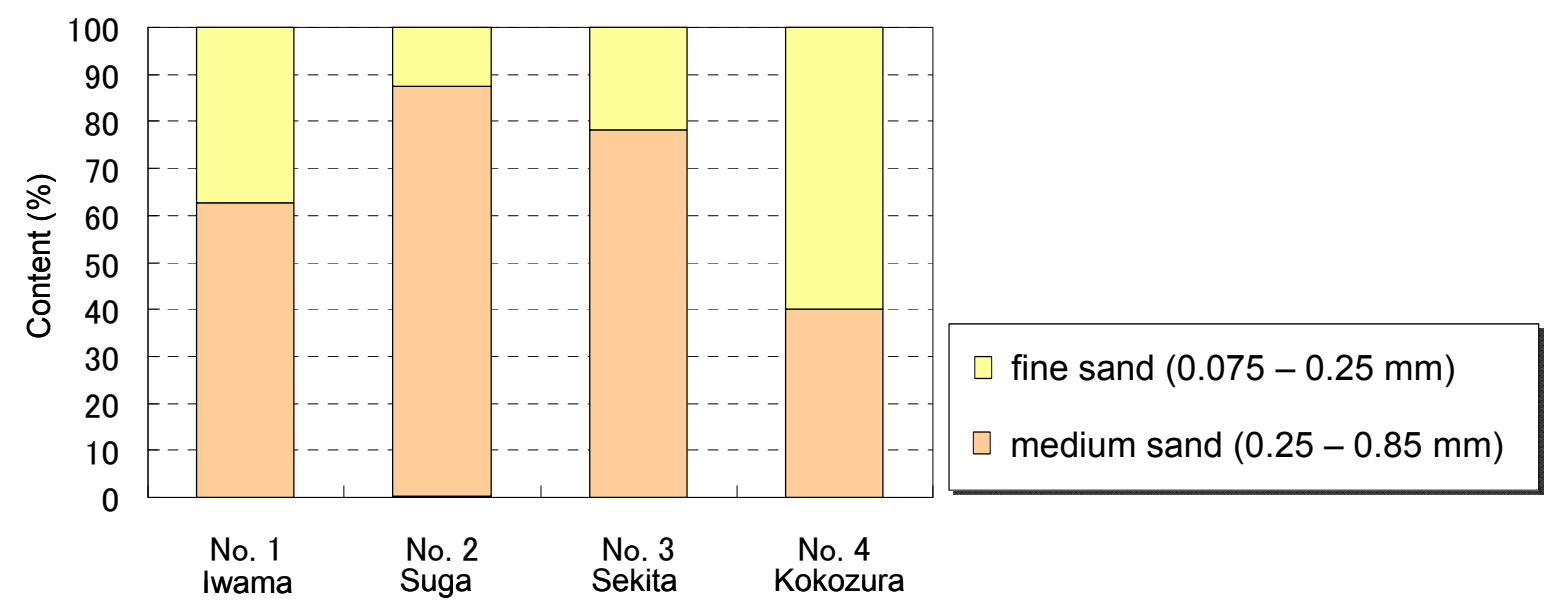

Figure 5. Composition of each grain size of foreshore materials. 


\section{REPRODUCTION OF BEACH CHANGES}

\section{Calculation conditions}

For the pocket beach under study, beach changes were considered to be due to the longshore imbalance of the sand budget; the sandy beach with a uniform width under natural conditions disappeared owing to the effect of longshore sand transport triggered by the construction of offshore breakwaters of fishing ports. The sand deposition and erosion zones were clearly separated with the deposition of sand at both ends and erosion in the central part of the study area. These beach changes were reproduced using the contour-line-change model developed by Serizawa et al. (2003).

The calculation domains are shown in Fig. 6. The wave field was calculated in a domain with a length of $11 \mathrm{~km}$ alongshore and a width of $6.5 \mathrm{~km}$ in the cross-shore direction, whereas the beach changes were calculated in a rectangular domain with a length of $6.6 \mathrm{~km}$ and a width of $2.0 \mathrm{~km}$ inside the calculation domain of the wave field.

For the wave conditions, the energy-mean waves with a significant wave height of $1.67 \mathrm{~m}$, wave period of $8.2 \mathrm{~s}$ and the predominant wave direction of $\mathrm{N} 116.2^{\circ}$, as shown in Fig. 7 , were used on the basis of wave observations between 2002 and 2007 at Onahama Port north of the study area. Here, Fig. 7 shows the energy ratio of the component waves for each direction relative to the entire wave energy with the most frequent wave direction of $\mathrm{N} 106^{\circ}$ and the predominant wave direction of $\mathrm{N} 116.2^{\circ}$. The offshore breakwater of Hirakata fishing port in Ibaraki Prefecture at the south end of the calculation domain, as shown in Fig. 6, had been extended by 2005, and these structural conditions were taken into account.

The initial bathymetry was determined on the basis of the shoreline configuration measured in 1975 when no coastal structures had yet been constructed because there were no bathymetric measurements in 1975. Because the seabed slope between the berm height and the depth of closure $h_{c}$ of -8 m measured in 2010 was 1/40, we assumed that the slope measured in 1975 was similar to the present slope. On the basis of the shoreline configuration measured in 1975, the initial bathymetry was assumed to have a uniform slope in the longshore direction. The seabed slope at depths greater than 8 m was assumed to be $1 / 200$. The berm height was determined from the relation $h_{R}=0.3 h_{c}$, which was obtained as an empirical relationship between the depth of closure and the berm height (Uda, 1997). When offshore breakwaters and artificial reefs are constructed, a wave-shelter zone is formed behind these structures. In such cases, the wave diffraction coefficient and wave direction in the vicinity of the wave-shelter zone can be obtained using the angular spreading method for irregular waves (Sakai et al., 2006) and then, the wave height is reduced by multiplying the breaker height without the offshore breakwaters by the wave diffraction coefficient. Furthermore, as the distribution of wave direction, the direction of diffracted waves can be used. The additional longshore sand transport due to the longshore change in breaker height was evaluated by the method given by Ozasa and Brampton (1980). Table 1 and Fig. 8 respectively show the calculation conditions and the initial bathymetry.

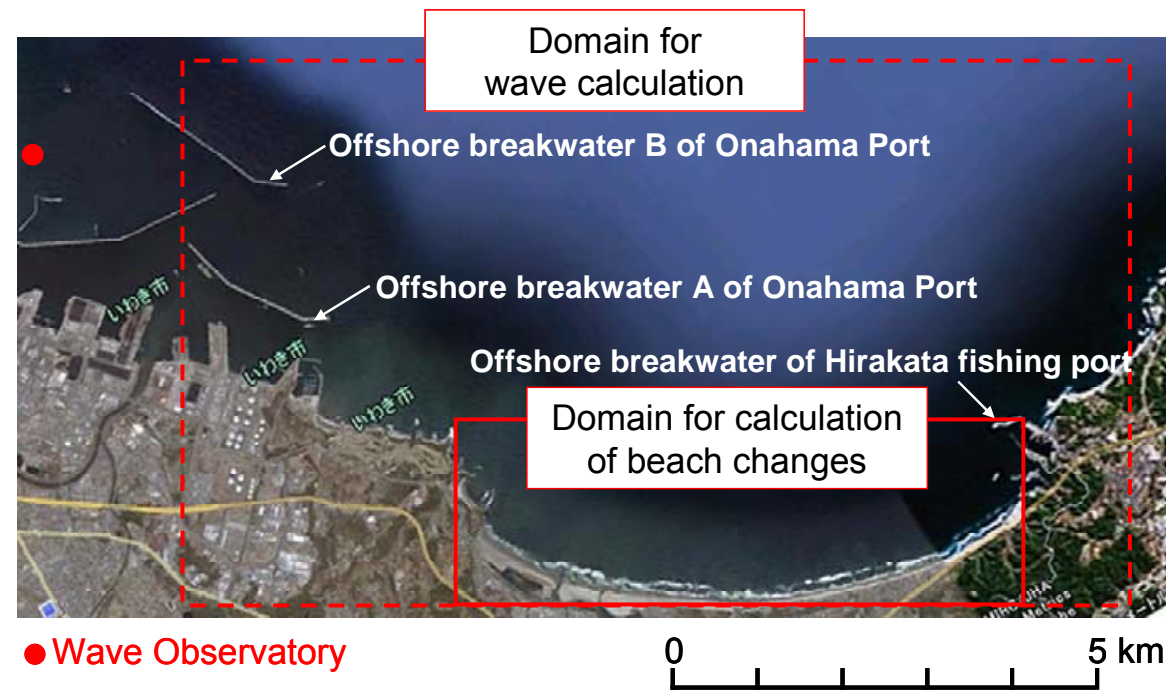

Figure 6. Calculation domains. 


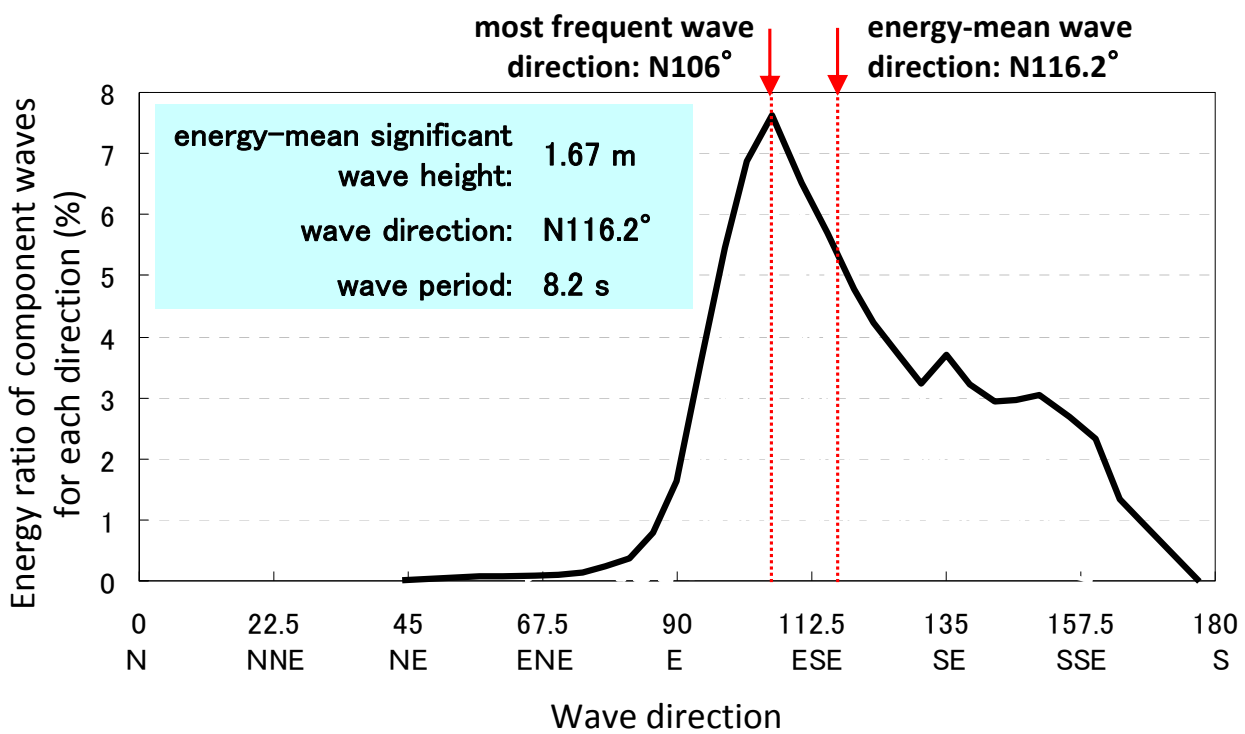

Figure 7. Energy ratio of component waves for each direction relative to the entire wave energy.

\begin{tabular}{|c|c|c|}
\hline \multicolumn{2}{|c|}{ Calculation method } & $\begin{array}{l}\text { Contour-line-change model for beach changes } \\
\text { (Serizawa et al., 2003) } \\
\text { Angular spreading method for irregular waves } \\
\text { (Sakai et al., 2006) }\end{array}$ \\
\hline \multicolumn{2}{|l|}{ Initial beach slope } & $\begin{array}{l}1 / 4 \text { between }+5 \text { and }-8 m \\
1 / 200 \text { between }-8 \text { and }-10 \mathrm{~m}\end{array}$ \\
\hline \multicolumn{2}{|l|}{ Equilibrium slope } & $1 / 40$ \\
\hline \multirow[t]{3}{*}{ Wave conditions } & Breaker height $H_{b}(\mathrm{~m})$ & 1.7 \\
\hline & Breaker angle $\alpha$ (deg.) & 0.0 \\
\hline & Tide level & M.S.L. $0.0 \mathrm{~m}$ \\
\hline \multicolumn{2}{|c|}{ Depth of closure $h_{c}(\mathrm{~m})$} & 8.0 \\
\hline \multicolumn{2}{|c|}{ Berm height $h_{R}(\mathrm{~m})$} & 3.0 \\
\hline \multicolumn{2}{|c|}{ Coefficient of sand transport $A$} & 0.2 \\
\hline \multicolumn{2}{|c|}{ Coefficient of Ozasa and Brampton (1980)'s term } & 1.6 \\
\hline \multicolumn{2}{|c|}{$\begin{array}{l}\text { Ratio between cross-shore and longshore sand } \\
\text { transports }\end{array}$} & 0.2 \\
\hline \multicolumn{2}{|c|}{ Critical slope of falling sand } & $1 / 2$ on land and $1 / 3$ on seabed \\
\hline \multirow{2}{*}{$\begin{array}{l}\text { Calculation } \\
\text { domain }\end{array}$} & Longshore direction & Between $X=0$ and $7 \mathrm{~km}$ \\
\hline & Vertical direction & Between $Z=+5$ and $-10 \mathrm{~m}$ \\
\hline \multirow[t]{2}{*}{ Mesh size } & $\Delta Y(\mathrm{~m})$ & 50 \\
\hline & $\Delta Z(\mathrm{~m})$ & 1 \\
\hline \multicolumn{2}{|c|}{ Time intervals $\Delta t(\mathrm{hr})$} & 1 \\
\hline \multicolumn{2}{|c|}{ Total number of steps per year } & 8,760 \\
\hline
\end{tabular}




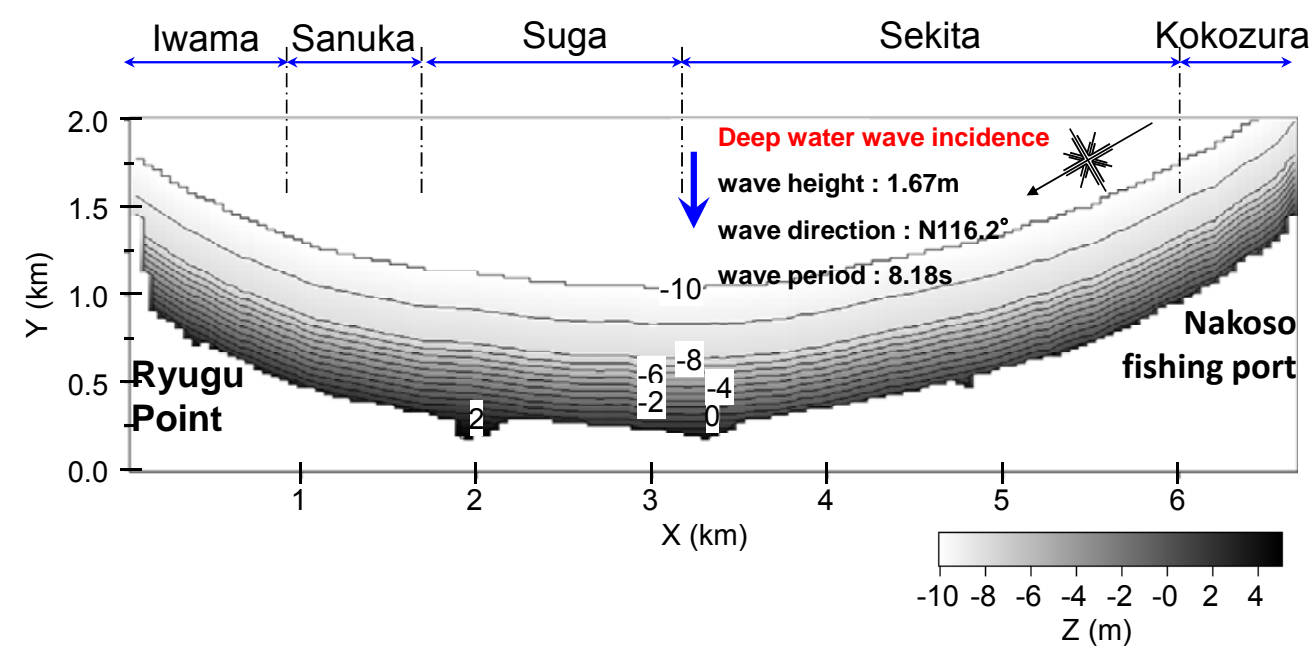

Figure 8. Initial bathymetry.

\section{Results}

The reproduction calculation was carried out given the initial bathymetry, as shown in Fig. 8, and the bathymetric and shoreline changes observed up to 1999 were reproduced after the construction of the artificial reefs with a crown height of $1.65 \mathrm{~m}$ below mean sea level and a width of $10 \mathrm{~m}$ on the Suga coast and the six detached breakwaters at the south end of the pocket beach. Figures 9, 10 and 11 show the reproduced bathymetry, the bathymetric changes between 1975 and 1999, and the measured and reproduced shoreline changes, respectively. Sand had been markedly deposited by 1999 near the south end of the pocket beach as well as on the Iwama coast located near the north end. Although the effect of the river discharge was not taken into account in this calculation, the shoreline advanced owing to the wave-sheltering effect of Ryugu Point. In contrast, on the Sekita coast, located in the central part of the pocket beach, erosion occurred because of the generation of southward longshore sand transport associated with the formation of the wave-shelter zone produced by the extension of Hirakata fishing port, although sand was locally deposited behind the artificial reef on the Suga coast. The measured and calculated shoreline changes are in good agreement.

Similarly, the beach changes observed until 2006, when the construction of the artificial reefs was fully completed. Figures 12, 13 and 14 show the predicted bathymetry in 2006, the bathymetric changes with reference to the bathymetry in 1975, and the measured and reproduced shoreline changes, respectively. The contours near both ends of the pocket beach further advanced with a small shoreline advance on the Suga coast because of the effect of the artificial reefs. The measured and predicted shoreline changes are in good agreement. These results indicate that the effect of the formation of the wave-shelter zone associated with the construction of the offshore breakwater of Hirakata fishing port is greater than that of the artificial reefs. The deposition of sand by the artificial reefs constructed in the central part of the pocket beach was less effective in preventing beach erosion.

In conclusion, the shoreline recession between the central part of the coast and its southern part, which occurred between 1980 and the 1990s, was found to be due to the extension of the offshore breakwater constructed in the southernmost area, beyond the jurisdiction of Fukushima Prefecture. Although much effort was spent in building artificial reefs with a crown height of $1.65 \mathrm{~m}$ below mean sea level and a width of $10 \mathrm{~m}$ as a measure against beach erosion by the shore protection agency of Fukushima Prefecture, their effect was limited because of successive erosion triggered by longshore sand transport toward the wave-shelter zone behind Hirakata fishing port. The seabed around the artificial reefs was deepened, causing difficulty in maintaining the wave-dissipating function of the artificial reefs.

As a measure, the case in which the offshore breakwater of Hirakata fishing port is demolished was simulated using the present model. The results clearly show that if we want to continue maintaining the fishing port, the sandy beach of the Sekita coast can never be recovered. This requires a choice between two alternatives, because the longshore sand transport from the erosion area to the wave-shelter zone is expected to continue as long as the offshore breakwater exists. 


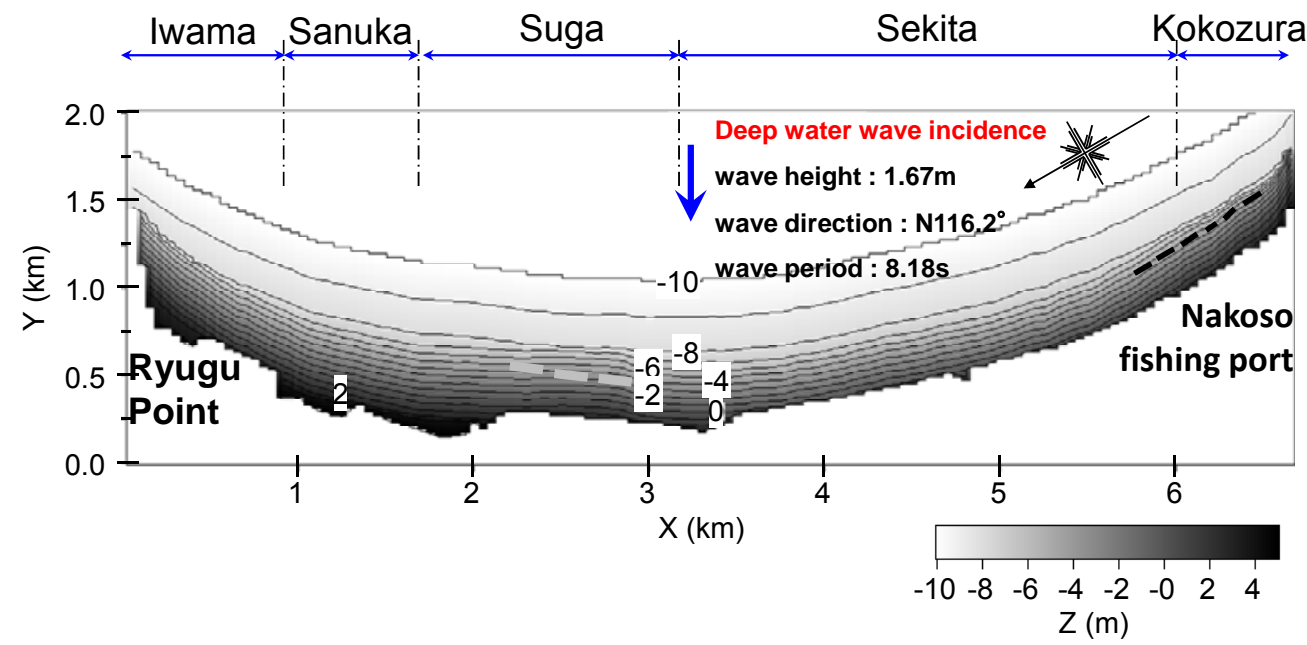

Figure 9. Calculation results up to 1999.

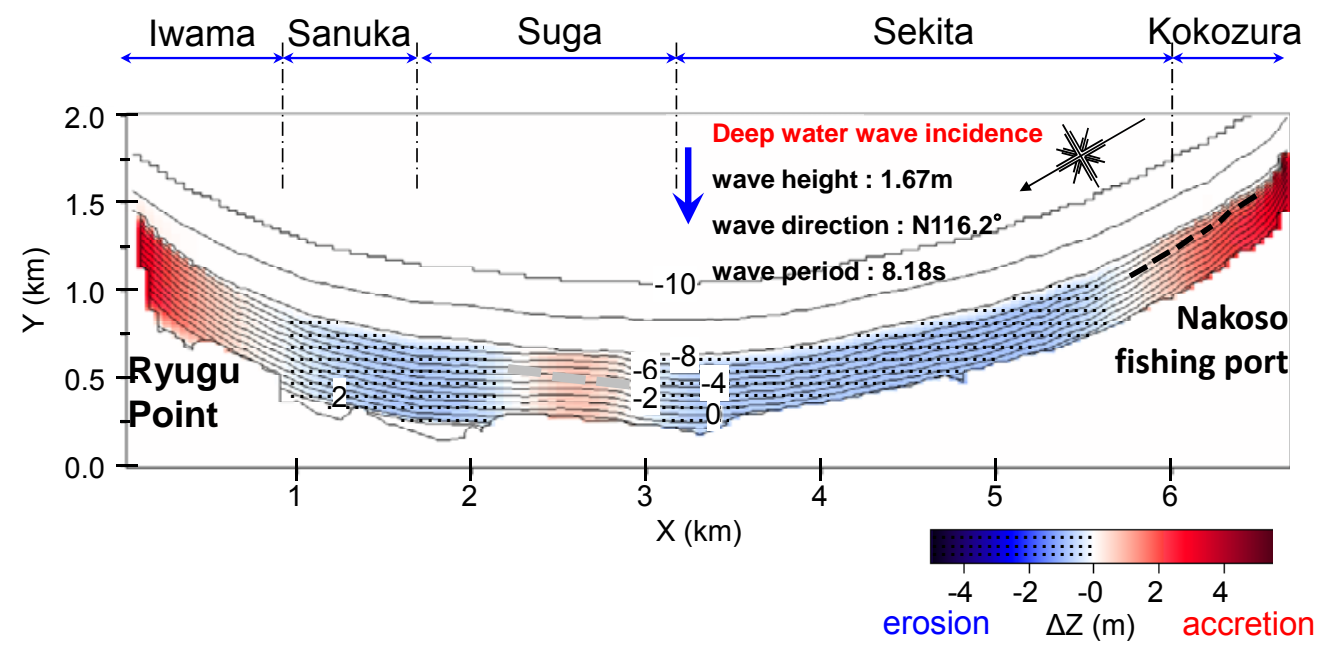

Figure 10. Bathymetric changes between 1975 and 1999.

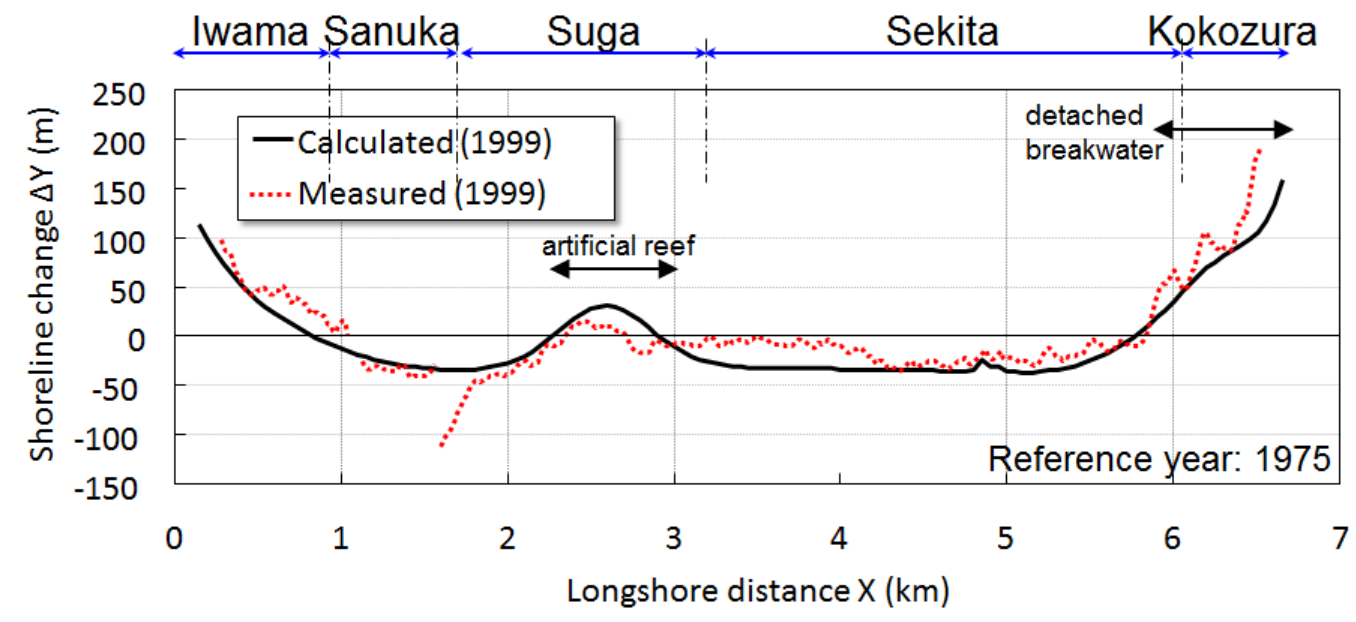

Figure 11. Measured and calculated shoreline changes until 1999. 


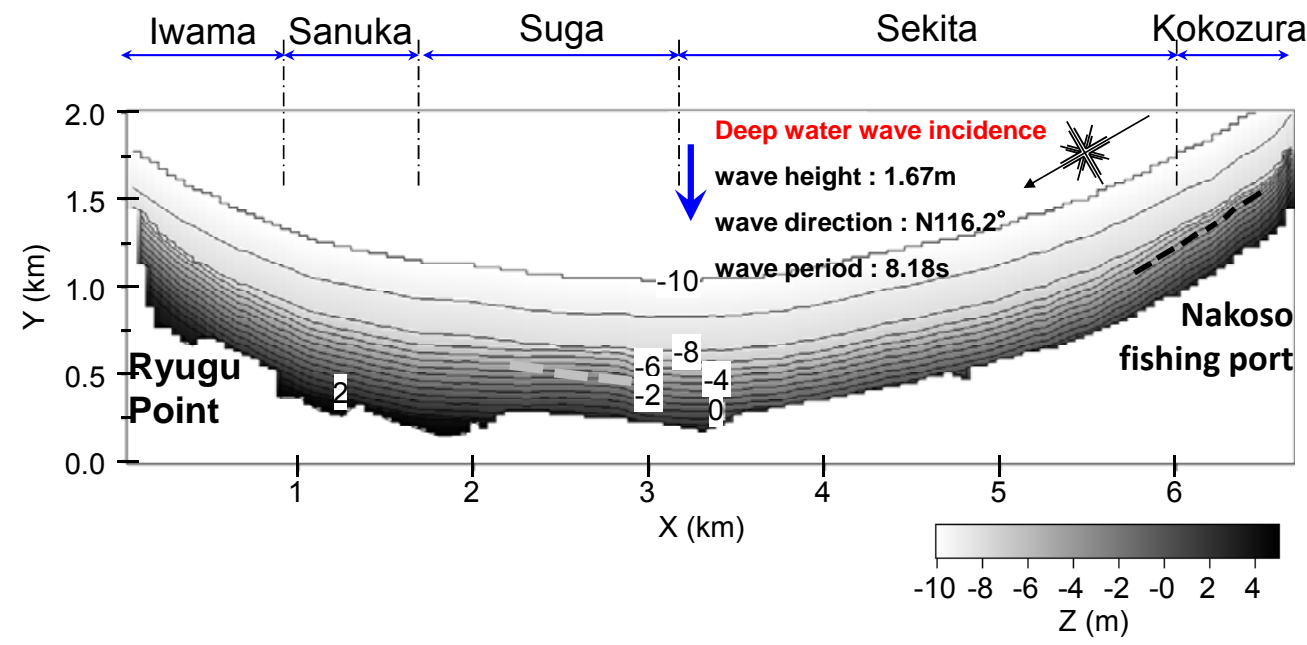

Figure 12. Calculation results up to 2006.

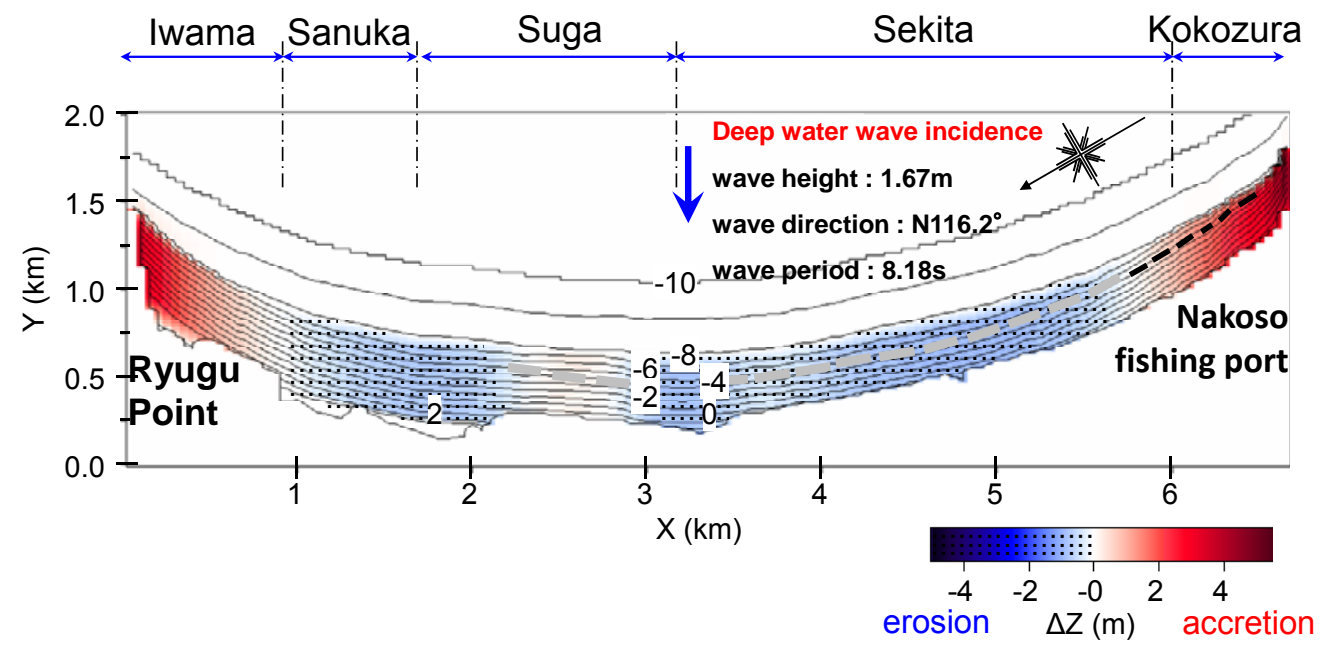

Figure 13. Bathymetric changes between 1975 and 2006.

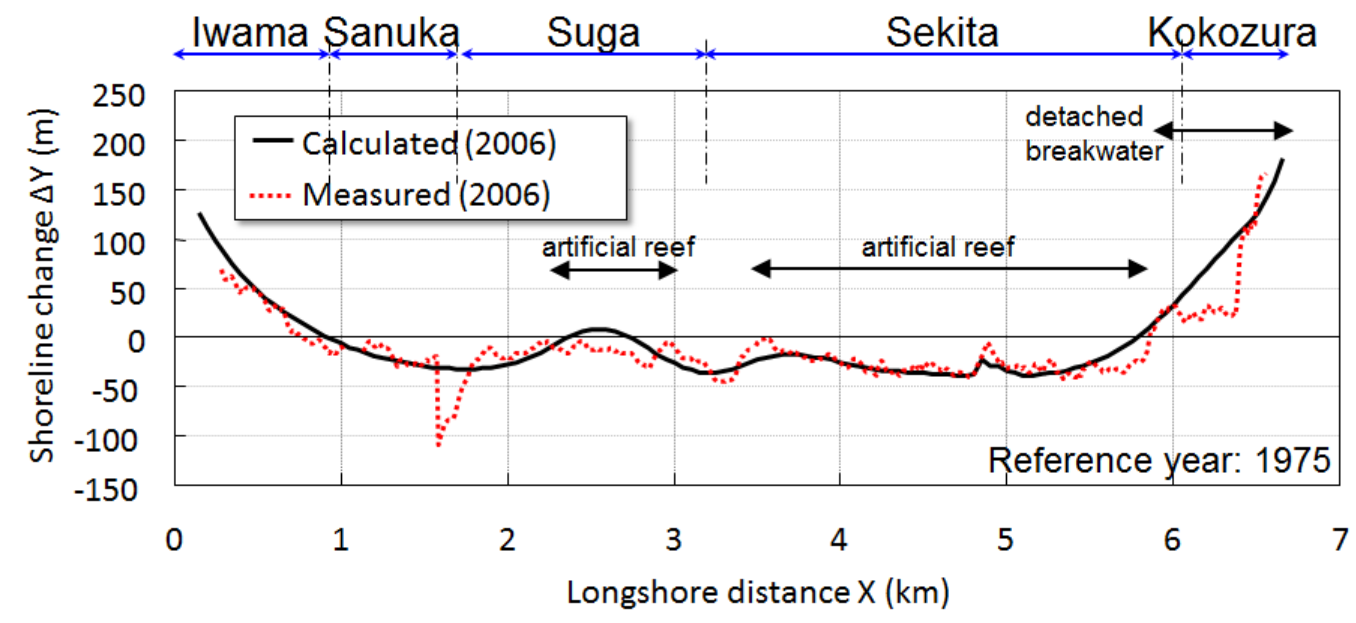

Figure 14. Measured and calculated shoreline changes until 2006. 


\section{CONCLUSION}

The shoreline recession that occurred between 1980 and the 1990s in the central and southern parts of a pocket beach of $6.5 \mathrm{~km}$ length bounded by Ryugu and Unoko Points at the north and south ends, respectively, in Fukushima Prefecture was found to be due to the extension of the offshore breakwater of Hirakata fishing port in Ibaraki Prefecture located south of Fukushima Prefecture. Although artificial reefs have been constructed on the Suga and Sekita coasts as a countermeasure, the sandy beach was not recovered on these coasts because the effect of the wave-shelter zone of the offshore breakwater of Hirakata fishing port is much larger than that of the artificial reefs. In conclusion, the effect of the artificial reefs constructed as a measure against beach erosion due to the wave-sheltering effect caused by the extension of a large-scale offshore breakwater is limited.

This study clearly demonstrates the necessity of comprehensive measures in an extensive area exceeding the jurisdiction of individual authorities separated by a sector-by-sector system to prevent and solve beach erosion, instead of local optimization using artificial reefs or detached breakwaters. Without considering fundamental issues, any engineering method focusing on only local issues is expected to eventually fail. This case is not an isolated example and the same situation can be found in many places on Japan's coasts (Uda, 2010). Discussions open to the public are necessary before the adoption of appropriate measures.

\section{REFERENCES}

Matsu-ura, T., T. Uda, T. Kumada, and M. Sumiya. 2010. Sand accumulation in wave-shelter zone of Oharai Port and change in grain size of seabed materials on nearby coast, Proc. $32^{\text {nd }}$ ICCE, sediment.63, pp. 1-11.

Ozasa, H., and A. H. Brampton. 1980. Model for predicting the shoreline evolution of beaches backed by seawalls, Coastal Eng., Vol. 4, pp. 47-64.

Sakai, K., T. Uda, M. Serizawa, T. Kumada, and Y. Kanda. 2006. Model for predicting threedimensional sea bottom topography of statically stable beach, Proc. $30^{\text {th }}$ ICCE, pp. 3184-3196.

Serizawa, M., T. Uda, T. San-nami, K. Furuike, and T. Kumada. 2003. Improvement of contour line change model in terms of stabilization mechanism of longitudinal profile, Coastal Sediments '03, pp. 1-15.

Uda, T. 1997. Beach Erosion in Japan, Sankaido, Tokyo, p. 442. (in Japanese)

Uda, T. 2010. Japan's Beach Erosion - Reality and Future Measures, World Scientific, p. 418. 